\title{
The effect of carbon nanotubes on epoxy matrix nanocomposites
}

\author{
Ewelina Ciecierska $\cdot$ Anna Boczkowska $\cdot$ \\ Krzysztof Jan Kurzydlowski • Iosif Daniel Rosca • \\ Suong Van Hoa
}

Received: 11 October 2011/ Accepted: 18 May 2012/Published online: 3 July 2012

(C) The Author(s) 2012. This article is published with open access at Springerlink.com

\begin{abstract}
The paper concerns thermal properties of epoxy/nanotubes composites for aircraft application. In this work, influence of carbon nanotubes on thermal stability, thermal conductivity, and crosslinking density of epoxy matrix was determined. Three kinds of nanotubes were used: non-modified with 1 - and $1.5-\mu \mathrm{m}$ length, and $1-\mu \mathrm{m}$ length modified with amino groups. Scanning electron microscopy observations were done for examining dispersion of nanotubes in the epoxy matrix. Glass transition temperature $\left(T_{\mathrm{g}}\right)$ was readout from differential scanning calorimetry. From dynamic mechanical analysis, crosslinking density was calculated for epoxy and its composites. Also, thermogravimetric analysis was done to determine influence of nanotubes addition on thermal stability and decomposition process of composites. Activation energy was calculated from TGA curves by Flynn-WallOzawa method. Thermal diffusivity was also measured. SEM images proved the uniform dispersion of carbon nanotubes without any agglomerates. It was found that nanotubes modified with amino groups lead to the increase of epoxy matrix crosslinking density. The significant increase in $T_{\mathrm{g}}$ was also observed. On the other hand, addition of carbon nanotubes leads to the decrease of thermal stability of polymer due to the increase of thermal diffusivity.
\end{abstract}

E. Ciecierska $(\bowtie) \cdot$ A. Boczkowska · K. J. Kurzydlowski Faculty of Materials Science and Engineering,

Warsaw University of Technology, Woloska Street 141, 02-507 Warszawa, Poland

e-mail: eciecierska@meil.pw.edu.pl

I. D. Rosca $\cdot$ S. Van Hoa

Concordia Center for Composites, Department of Mechanical

and Industrial Engineering, Concordia University,

1515 Ste. Catherine West \# 4-145, Montreal, QC, Canada
Keywords Nanocomposites - Carbon nanotubes . Polymer matrix composites - Thermal properties . Activation energy $\cdot$ Crosslinking density

\section{Introduction}

Carbon nanotubes, CNTs, owing to their attractive mechanical, thermal, and electrical properties have found a wide range of applications, including nanomodifier of polymer composites. Main challenge in manufacturing nanocomposites is the uniform dispersion of CNTs in polymer matrix, often realized via calendering and/or sonification [1,2]. To improve the adhesion of CNTs to the polymer matrix, their surface is frequently functionalized by amino or carboxyl groups.

Epoxy resin is often used as a matrix of fiber-reinforced composites for advanced applications. Addition of CNTs results in a significant improvement of epoxy resin, in particular in an increase of the electrical conductivity by a few orders of magnitude. This is accompanied by an increase of thermal conductivity $[3,4]$. On the other hand, some results indicate that the addition of carbon nanotubes may deteriorate thermal stability of the epoxy matrix $[5,6]$. It has been also reported that modification with nanotubes changes glass transition temperature, $T_{\mathrm{g}}$ [7], which in the case of the CNTs functionalised with amino groups considerably increases [8]. In this context, the aim of this work was to investigate the thermal properties of epoxy-nanotube composites with CNTs of different lengths and subjected to different surface functionalization. To this end, several thermal characteristics have been measured for epoxy/CNTs nanocomposites. These characteristics and the results of the microstructure investigations are discussed in terms of the effect of CNTs on the epoxy matrix of nanocomposites. 


\section{Experimental}

\section{Materials}

The multi-wall carbon nanotubes, with oxides content of $5 \mathrm{wt} \%$, were supplied by Nanocyl Inc. (Belgium). CNTs with two lengths, 1.5 and $1.0 \mu \mathrm{m}$ were employed. Part of the $1 \mu \mathrm{m}$ CNTs were functionalized with amino groups. Average tube diameter in each case was equal to $9.5 \mathrm{~nm}$. The CNTs were dispersed in the epoxy resin EPON 862 (diglycidyl ether of bisphenol-F) supplied by Hexion. EPIKURE W (aromatic di-amine) was used as the curing agent. The Stoichiometric ratio of EPON 862 to EPICURE W was 100:26.4 by weight.

Samples of nanocomposites were prepared with nanotubes weight fraction varying from 1 to $5 \%$. The resin, curing agent, and CNTs were first mixed manually and subsequently with three-roll mill. First, the mixture was stirred under a gap of $50 \mu \mathrm{m}$ and $100 \mathrm{rpm}$. For second stirring, 20- $\mu \mathrm{m}$ gap was used. Finally, the mixture was stirred three times with $10-\mu \mathrm{m}$ gap. After stirring, the mixture was placed into a mold and was degassed and cured for $6 \mathrm{~h}$ at $130{ }^{\circ} \mathrm{C}$.

\section{Measurements}

Microstructure observations were performed using Scanning Electron Microscope HITACHI S5500. Differential scanning calorimetry was carried out using DSC Q1000 (TA). Thermal diffusivity was measured using LFA 447 NanoFlash (NETZSCH). Thermal properties were also examined using thermogravimetric analyzer TGA Q500 (TA) in the temperature ranging from 25 to $600{ }^{\circ} \mathrm{C}$ under nitrogen. Heating rate was $5{ }^{\circ} \mathrm{C}$ per minute. Activation energy was calculated from TG curves for four heating rates: 5, 10, 15, and $20{ }^{\circ} \mathrm{C} \min ^{-1}$. Dynamic mechanical analysis was made using DMA 983 (TA) in the temperature range of RT to $220{ }^{\circ} \mathrm{C}$. Rate of heating was $2{ }^{\circ} \mathrm{C} \mathrm{min}{ }^{-1}$. Crosslinking density was determined from dynamic mechanical analysis by calculating the average molar mass of elastically effective chains between crosslinks $\left(M_{\mathrm{c}}\right)$ by Eq. $1[9,10]$ :

$E \approx \frac{3 \rho R T}{\overline{M_{\mathrm{c}}}}$

where $E$ is the elastic modulus in $20{ }^{\circ} \mathrm{C}$ above $T_{\text {c }}$ determined from DMA curves as it is shown in Fig. 3, $T_{\mathrm{c}}$ is the extrapolated temperature when $E$ slightly decreases [K], $\rho$ is the polymer density, $R$ is the gas constant, and $T$ is the absolute temperature.

\section{Results and discussion}

Microstructure of the samples was investigated via SEM observations of the brittle fracture surfaces obtained by impact loading of the samples cooled to the temperature of liquid nitrogen. Representative images obtained in this way are presented in Fig. 1. They provide evidence of the uniform dispersion of carbon nanotubes in the epoxy matrix independently of their length and surface modification. The SEM images also proved that calendering employed in this work leads to the even distribution of CNTs into epoxy matrix.

DSC curves for epoxy resin and the composites are shown in Fig. 2 and the values of glass transition temperature calculated from the curves are listed in Table 1.

The results shown in Table 1 demonstrate that the addition of carbon nanotubes with amino groups leads to the increase of the glass transition temperature. This can be caused by the reaction between amino groups located on the CNTs' surface and epoxide groups of the epoxy resin although the amount of functional groups on the nanotubes surface is only $0.5 \%$ by weight. Such small amount of amino groups should not have influence on the crosslinking density, especially when it is compared to curing agent amount (20 wt\%). The effect of the CNTs on the matrix is caused by the high specific surface area of CNTs per the unit volume of a composite, $S_{\mathrm{V}}$. The value of $S_{\mathrm{V}}$ parameter was estimated from purely geometrical considerations. Surface of an individual carbon nanotube is given by Eq. 2:

$S=2\left(\pi r L+\pi r^{2}\right)$

where $L$ is the length of the tube and $\mathrm{r}$ is its radius $(r \ll L)$.

A given weight fraction of the nanotubes was converted into its volume fraction, $V_{\mathrm{V}}$, by means of Eq. 3:

$V_{\mathrm{V}}=\frac{V_{\mathrm{CNT}}}{V_{\mathrm{CNT}}+V_{\text {polimer }}}=0.88 \%$

Volume of a single tube can be approximated as $V \approx \pi r^{2} L$.

The number of CNTs (for $1 \mathrm{wt} \%$ of CNT) in the unit volume $\left(N_{\mathrm{v}}\right)$ is given by Eq. 4:
Fig. 1 SEM images of the composites with different kind of nanotubes: a $1.5-\mu \mathrm{m}$ nonmodified, b $1-\mu \mathrm{m}$ non-modified, c $1-\mu \mathrm{m}$ nanotubes modified with amino groups
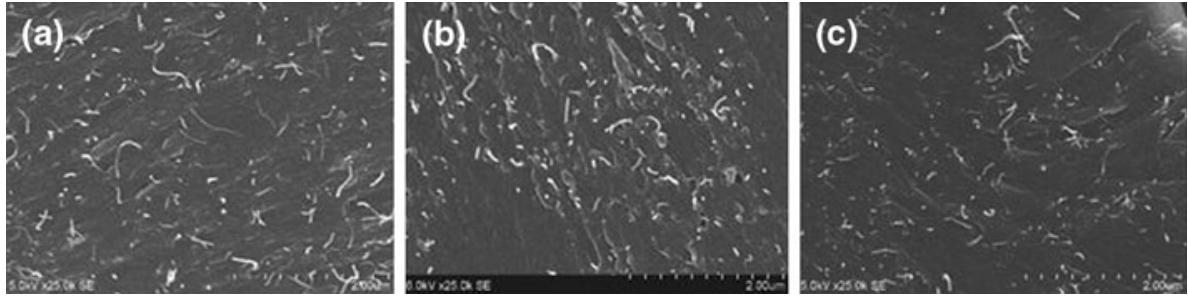
Fig. 2 DSC curves of composites with a $1.5-\mu \mathrm{m}$ non-modified nanotubes, b $1-\mu \mathrm{m}$ non-modified nanotubes, c $1-\mu \mathrm{m}$ nanotubes modified with amino groups
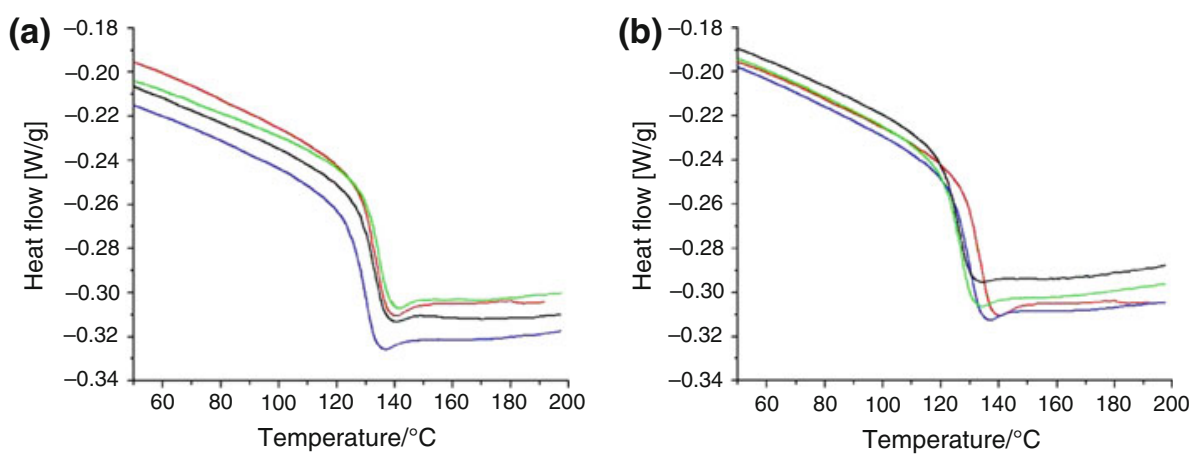
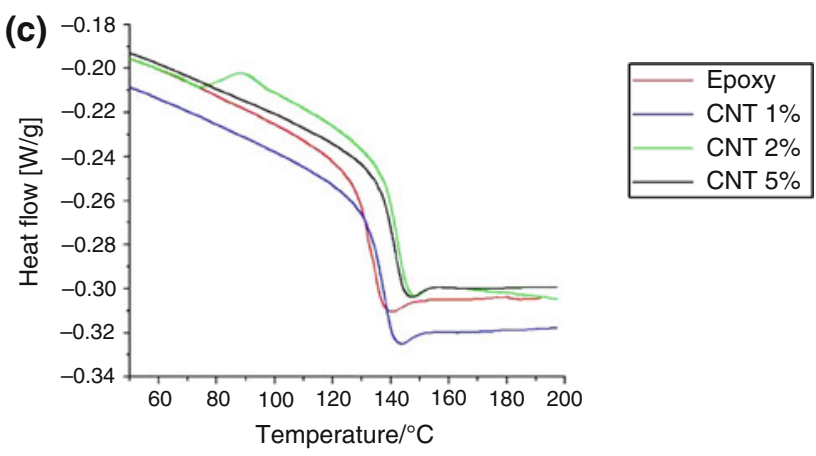

Table 1 Glass transition temperature of epoxy and epoxy-nanotube composites with different amount and different kind of nanotubes

\begin{tabular}{|c|c|c|c|c|c|c|c|c|c|c|}
\hline \multirow[t]{2}{*}{ Sample } & \multirow[t]{2}{*}{ Epoxy } & \multicolumn{3}{|c|}{$\begin{array}{l}\text { Composites with non-modified } \\
\text { nanotubes } 1-1.5 \mu \mathrm{m}\end{array}$} & \multicolumn{3}{|c|}{$\begin{array}{l}\text { Composites with non-modified } \\
\text { nanotubes } 1-1 \mu \mathrm{m}\end{array}$} & \multicolumn{3}{|c|}{$\begin{array}{l}\text { Composites with nanotubes with amino } \\
\text { groups } 1-1 \mu \mathrm{m}\end{array}$} \\
\hline & & $1 \%$ & $2 \%$ & $5 \%$ & $1 \%$ & $2 \%$ & $5 \%$ & $1 \%$ & $2 \%$ & $5 \%$ \\
\hline$T_{\mathrm{g}}\left({ }^{\circ} \mathrm{C}\right)$ & $133 \pm 0.5$ & $129 \pm 0.5$ & $134 \pm 0.5$ & $132 \pm 0.5$ & $130 \pm 0.5$ & $127 \pm 0.5$ & $126 \pm 0.5$ & $137 \pm 0.5$ & $142 \pm 0.5$ & $141 \pm 0.5$ \\
\hline
\end{tabular}

$N_{\mathrm{V}}=\frac{V_{\mathrm{V}}}{V}=\frac{V_{\mathrm{V}}}{\pi r^{2} L}$

The specific surface area of CNTs per unit volume of composite is equal to $1.853[1 / \mu \mathrm{m}]$, which was calculated from Eq. 5, where $r=0.0095 \mu \mathrm{m}$ :

$S_{\mathrm{V}}=N_{\mathrm{V}} S=\frac{V_{\mathrm{V}}(2 \pi r L)}{\left(\pi r^{2} L\right)}=\frac{2 V_{\mathrm{V}}}{r}$

High surface area of carbon nanotubes is the most probable reason of significant changes of the nanocomposites mechanical as well as thermal properties due to the interaction between carbon nanotubes and polymer macromolecules. When CNTs' surface is modified with reactive amino groups, the macromolecules lose their flexibility in the area around tubes due to the chemical reaction between $-\mathrm{NH}_{2}$ and oxarine ring of epoxy resin during curing reactions. Equations 2-5 consider ideal cylinders with length and diameter equal to the average data furnished by the CNT producer.

The average molar mass of the elastically effective chains between crosslinks $\left(M_{\mathrm{c}}\right)$ was determined from DMA studies to analyze the influence of carbon nanotubes on the crosslinking density. It is known from the literature that crosslinking density can be obtained by DMA by calculating $M_{\mathrm{c}}$ [11]. Equation 1 is poor the approximation for the composite materials. Although this is a rough method for crosslinking density determination, it is the only one available on a practical level. From DMA curves, storage modulus was obtained in the way

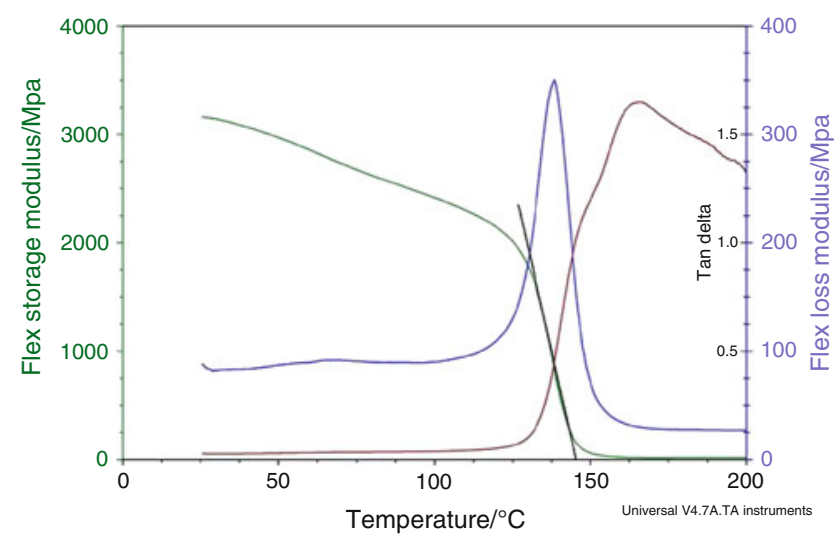

Fig. 3 DMA curve of epoxy resin with determined storage modulus 
Table 2 Average molar mass of elastically effective chains of epoxy resin and epoxy-nanotubes composites with different amount and kind of nanotubes

\begin{tabular}{|c|c|c|c|c|}
\hline Sample & $\begin{array}{l}\text { Weight } \% \\
\text { of CNTs }\end{array}$ & $\begin{array}{l}\rho / \\
\mathrm{g} \mathrm{cm}^{-3}\end{array}$ & $\begin{array}{l}E^{\prime} / \\
\mathrm{MPa}\end{array}$ & $\begin{array}{l}M_{\mathrm{c}} / \\
\mathrm{g} \mathrm{mol}^{-1}\end{array}$ \\
\hline Epoxy & 0 & 1.1972 & 19.02 & 685 \\
\hline \multirow{3}{*}{$\begin{array}{l}\text { Composites with non- } \\
\text { modified nanotubes } \\
1-1.5 \mu \mathrm{m}\end{array}$} & 0.1 & 1.1994 & 18.22 & 713 \\
\hline & 1.0 & 1.1977 & 24.90 & 517 \\
\hline & 2.0 & 1.1996 & 36.60 & 358 \\
\hline \multirow{2}{*}{$\begin{array}{l}\text { Composites with } \\
\text { non-modified }\end{array}$} & 0.1 & 1.1959 & 15.32 & 833 \\
\hline & 1.0 & 1.1939 & 24.88 & 517 \\
\hline nanotubes $1-1 \mu \mathrm{m}$ & 2.0 & 1.1939 & 31.63 & 403 \\
\hline \multirow{3}{*}{$\begin{array}{l}\text { Composites with } \\
\text { nanotubes with } \\
\text { amino groups } \\
1-1 \mu \mathrm{m}\end{array}$} & 0.1 & 1.1925 & 23.97 & 556 \\
\hline & 1.0 & 1.1977 & 36.67 & 360 \\
\hline & 2.0 & 1.1973 & 40.62 & 329 \\
\hline
\end{tabular}

shown in Fig. 3, and by Eq. 1 the average molar mass between crosslinks was calculated. The results are listed in Table 2.
The average molar mass of chains between crosslinks $\left(M_{\mathrm{c}}\right)$ significantly decreases after the addition of carbon nanotubes modified with amino groups, which means that the crosslinking density increases due to the reaction between reactive amino groups and oxarine ring of epoxy resin. With the addition of non-modified carbon nanotubes, the crosslinking density decreases for the small amount of CNTs. However, at higher nanotube content, it increases. For higher nanotube content, an obtained significant increase of specific surface of nanotubes affects the macromolecules and prevents the free movement of polymer chains. The free volumes between macromolecules are occupied by carbon nanotubes; therefore, chains are much more squeezed and crosslinking density increases.

Thermogravimetric curves of nanocomposites are shown in Fig. 4. These curves differ in the decomposition rate and mass residue. The temperature of $5 \%$ of mass loss was chosen to define the matrix decomposition temperature. The values of such defined decomposition temperature,
Fig. 4 Thermogravimetric curves of composites with a $1.5-\mu \mathrm{m}$ non-modified nanotubes, b 1- $\mu \mathrm{m}$ nonmodified nanotubes, $\mathbf{c} 1-\mu \mathrm{m}$ nanotubes modified with amino groups
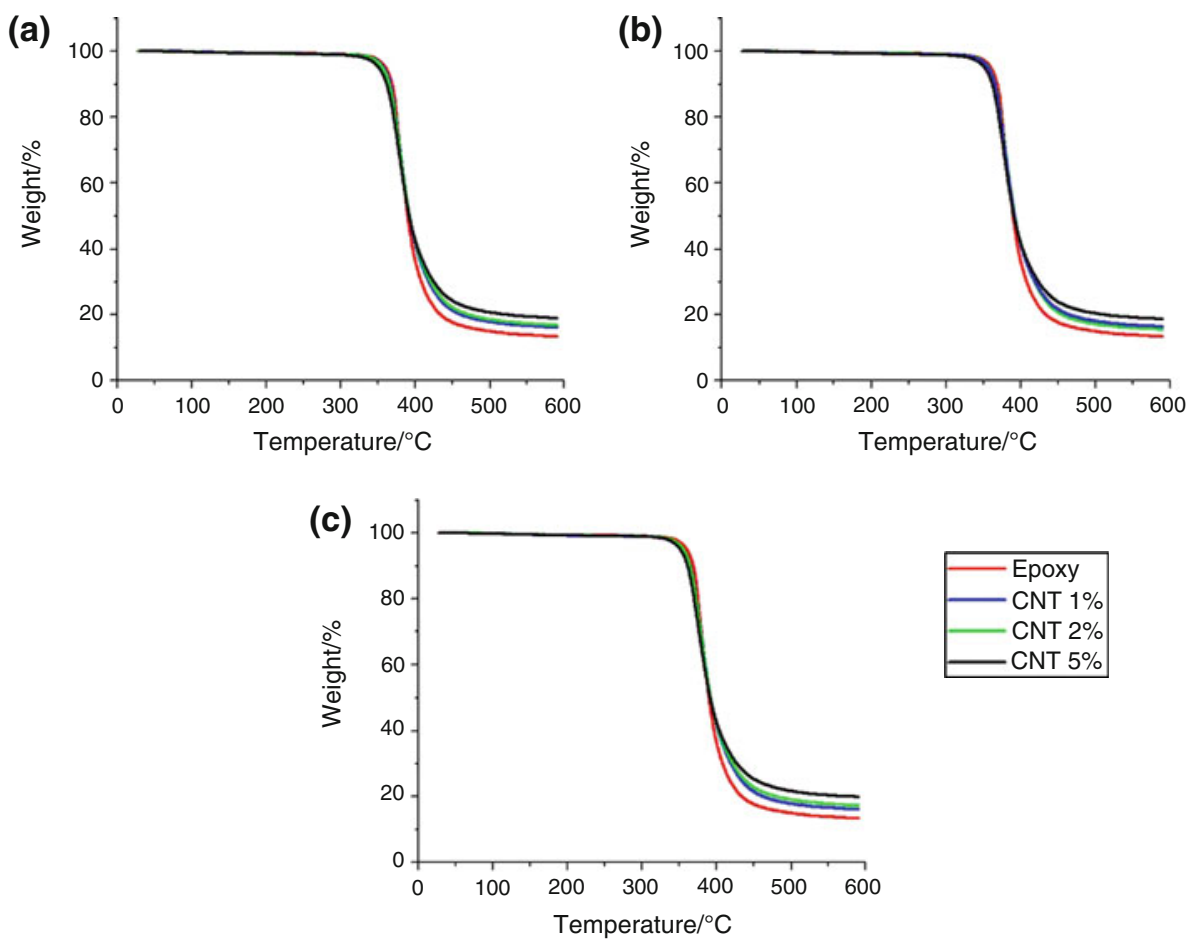

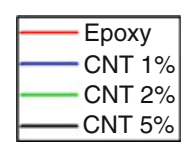

Table 3 Temperature of 5 mass\% loss of epoxy and epoxy-nanotube composites with different amount and kind of nanotubes

\begin{tabular}{|c|c|c|c|c|c|c|c|c|c|c|}
\hline \multirow[t]{2}{*}{ Sample } & \multirow[t]{2}{*}{ Epoxy } & \multicolumn{3}{|c|}{$\begin{array}{l}\text { Composites with non-modified } \\
\text { nanotubes } 1-1.5 \mu \mathrm{m}\end{array}$} & \multicolumn{3}{|c|}{$\begin{array}{l}\text { Composites with non-modified } \\
\text { nanotubes } 1-1 \mu \mathrm{m}\end{array}$} & \multicolumn{3}{|c|}{$\begin{array}{l}\text { Composites with nanotubes with } \\
\text { amino groups } 1-1 \mu \mathrm{m}\end{array}$} \\
\hline & & $1 \mathrm{wt} \%$ & $2 \mathrm{wt} \%$ & $5 \mathrm{wt} \%$ & $1 \mathrm{wt} \%$ & $2 \mathrm{wt} \%$ & $5 \mathrm{wt} \%$ & $1 \mathrm{wt} \%$ & $2 \mathrm{wt} \%$ & $5 \mathrm{wt} \%$ \\
\hline $\begin{array}{l}\text { Temperature } \\
\text { of } 5 \text { mass } \% \\
\text { loss }\left({ }^{\circ} \mathrm{C}\right)\end{array}$ & $360 \pm 0.5$ & $358 \pm 0.5$ & $356 \pm 0.5$ & $351 \pm 0.5$ & $357 \pm 0.5$ & $357 \pm 0.5$ & $352 \pm 0.5$ & $355 \pm 0.5$ & $355 \pm 0.5$ & $350 \pm 0.5$ \\
\hline
\end{tabular}


calculated from the thermogravimetric curves, are listed in Table 3.

For all studied composites, the decomposition temperature decreases with the increase of the carbon nanotubes' weight fraction. This results in a decrease in the thermal stability of polymers as a side effect of nanotube addition. Similar results were reported in $[5,6,12,13]$. The nanotubes' length and modification with 13 amino groups have no significant influence on the decomposition temperature. The decrease in the temperature of $5 \%$ weight loss is caused by the increase of thermal conductivity of polymer as an effect of CNTs addition. Carbon nanotubes increase the heat diffusion which results in faster degradation of polymer. The influence of CNTs' weight fraction on thermal diffusivity of composites is shown in Fig. 7.

The kinetics of the decomposition processes have been characterized by the activation energy calculated from TGA curves by the method proposed by Flynn-Wall-Ozawa, FWO. The Flynn-Wall-Ozawa model provides the following equation:

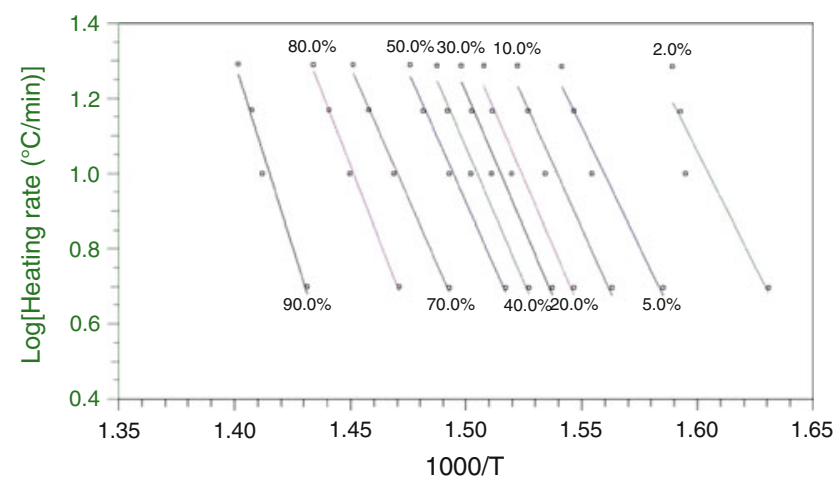

Fig. 5 The dependence of logarithm of heating rate versus reciprocal absolute temperature for the FWO method at indicated conversions of the epoxy resin $\log (q)=\log \left[\frac{A E_{\mathrm{a}}}{g(a) R}\right]-2.315-\frac{0.457 E_{\mathrm{a}}}{R T_{\mathrm{p}}}$

where $g(a)$ is a function of degree of cure $\alpha, q$ is the heating rate, and $T_{\mathrm{p}}$ is the peak exothermal temperature [14].

In this case, an ASTM Standard E164 was used. For this purpose, several TGA curves were collected at different heating rates. In the case of reported studies, the rates were varied from 5 to $20^{\circ} \mathrm{C} \mathrm{min}^{-1}$.

The logarithm of the heating rate was plotted versus $1 / T$ for a few degrees of the conversion of epoxy resin as shown in Fig. 5. The activation energy was calculated by means of a TA Instrument software as $E_{\mathrm{a}}=-$ slope $\times$ $R / 0.457$ (where $R$ is gas constant) [15]. The results of calculations are shown in Fig 5 .

For all investigated nanocomposites, the activation energy is lower for all conversion degrees in comparison to neat epoxy resin. It means that addition of CNTs increases the material's degradation efficiency. CNTs exhibit high thermal conductivity; they help to transport heat in composites, which reduces the activation energy. However, further investigations to explain the mechanism of the degradation will be carried out (Fig. 6).

The studies shown in Fig. 7 confirmed the increase of thermal diffusivity of nanocomposites in comparison to the epoxy matrix. Moreover, thermal diffusivity depends on the CNTs' weight fraction and length.

Thermal diffusivity increases with the increase of carbon nanotubes' weight fraction because nanotubes exhibit very good thermal conductivity. Addition of $5 \mathrm{wt} \%$ of CNTs to the epoxy resin almost doubles the thermal diffusivity. Higher thermal diffusivity was also obtained for composites with longer nanotubes. Longer carbon nanotubes create percolated network much easier than shorter one. The same tendency was reported in the literature [16].
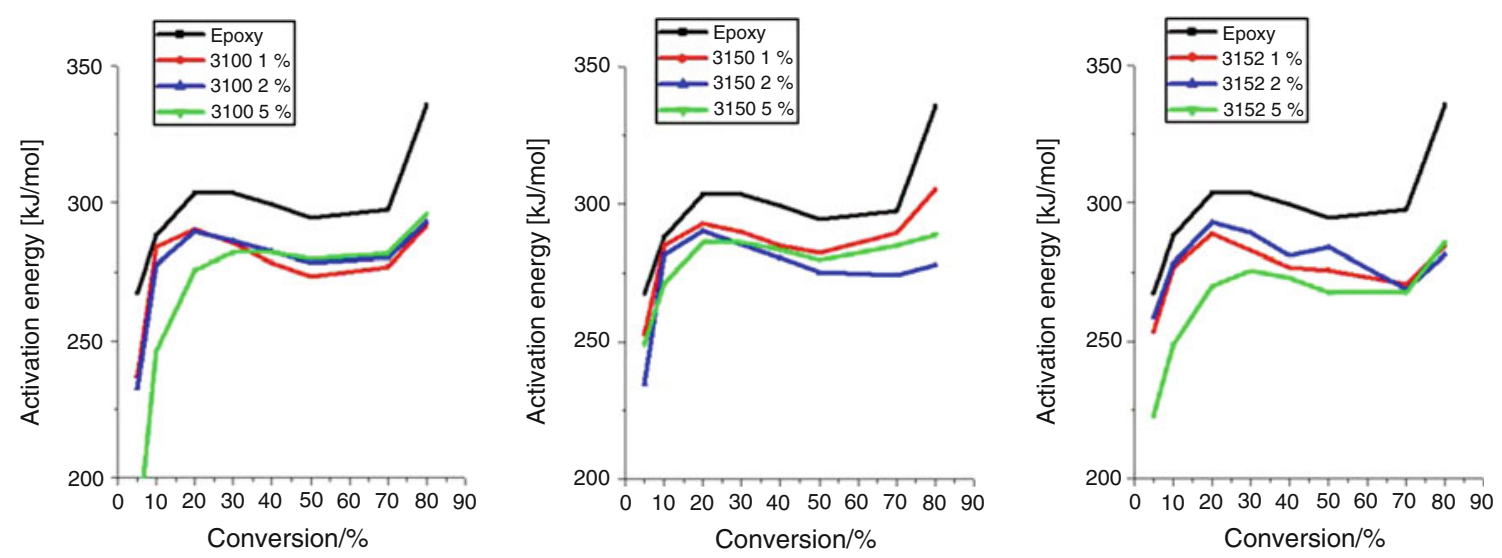

Fig. 6 Activation energy of the composites with a 1.5- $\mu \mathrm{m}$ non-modified nanotubes, $\mathbf{b} 1-\mu \mathrm{m}$ non-modified nanotubes, $\mathbf{c} 1-\mu \mathrm{m}$ nanotubes modified with amino groups 


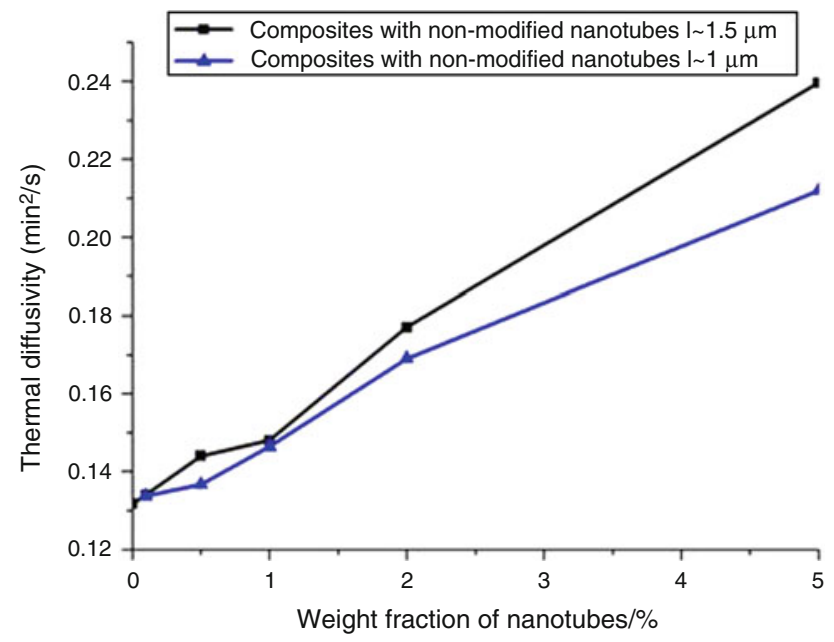

Fig. 7 Thermal diffusivity of composites with different kind of nanotubes

\section{Conclusions}

It was found that the addition of carbon nanotubes to the epoxy matrix affects the thermal properties of nanocomposites. Moreover, the reported influence depends on the carbon nanotubes' surface modification and also on their length.

The obtained results proved that the addition of carbon nanotubes with amino groups leads to the increase of the glass transition temperature as well as crosslinking density as an effect of the reaction between amino and hydroxyl reactive groups. Although the weight fraction of amino groups on the carbon nanotubes surface seems to be negligible in comparison to the weight fraction of curing agent, the influence is recordable due to the high specific surface area of nanotubes.

SEM observations confirmed that calendering leads to the good and uniform dispersion of carbon nanotubes in the epoxy matrix independently on their length and surface modification.

The results shown in this paper also confirmed that the addition of carbon nanotubes leads to the decrease in thermal stability of epoxy matrix as an effect of thermal conductivity increase.

Thermal diffusivity of nanocomposites increases with the increase of carbon nanotubes' weight fraction and their length. This also leads to the lower energy needed for the decomposition of nanocomposites.

Acknowledgements This work has been supported by the European Union in the framework of European Social Fund through the Warsaw University of Technology Development Programme.
Open Access This article is distributed under the terms of the Creative Commons Attribution License which permits any use, distribution, and reproduction in any medium, provided the original author(s) and the source are credited.

\section{References}

1. Heimann M, Wirts-Ruetters M, Boehme B, Wolter K-J. Investigations of Carbon Nanotubes Epoxy Composites for Electronics Packaging; 2008 Electronic Components and Technology Conference, p. 1731-1736.

2. Bauhofer W, Kovacs JZ. A review and analysis of electrical percolation in carbon nanotube polymer composites. Compos Sci Technol. 2009;69:1486-98.

3. Thostenson ET, Chou TW. Processing-structure-multi-functional property relationship in carbon nanotube/epoxy composites. Carbon. 2006;44:3022-9.

4. Yang Y, Gupta MC, Zalameda JN, Winfree WP. Dispersion behavior, thermal and electrical conductivities of carbon nanotubepolystyrene nanocomposites. Micro Nano Lett. 2008;3(2):35-40.

5. Loos MR, Ferreira Coelho LA, Pezzin SH, Amico SC. Effect of carbon nanotubes addition on the mechanical and thermal properties of epoxy matrices. Mater Res. 2008;11(3):347-52.

6. Zhou Y, Pervin F, Lewis L, Jedlani H. Experimental study on the thermal and mechanical properties of multi-walled carbon nanotube-reinforced epoxy. Mater Sci Eng A. 2007;452-453:657-64.

7. Grady BP, Paul A, Peters JE, Ford WT. Glass transition behavior of single-walled carbon nanotube-polystyrene composites. Macromolecules. 2009;42:6152-8.

8. Gojny FH, Schulze K. Functionalisation effect on the thermomechanical behaviour of multi-wall carbon nanotube/epoxycomposites. Compos Sci Technol. 2004;64:2303-8.

9. De Groote Ph, Roose P, Randoux Th, Van den Branden S, Demerteau W. Surface Specialities UCB, Belgium, Evolution of Visco-elastic Properties and Crosslinking Density of Radiationcured Coatings with Conversion. http://lejradt.vm139.remotion. nl/files_content/june\%202004\%20papers/grootepaperjune2004. pdf. Accessed 31.01.2012

10. Gude MR, Prolongo SG, Urena A. Effect of the epoxy/amine stoichiometry on the properties of carbon nanotube/epoxy composites. J Therm Anal Calorim. 2011;. doi:10.1007/s10973-0112056-x.

11. Pascault J-P, et al. Chap 10 of thermosetting polymers. New York: Marcel Dekker Inc.; 2002.

12. Zhou YX, Wu PX, Cheng Z-Y, Ingram J, Jeelani S. Improvement In electrical, thermal and mechanical properties of epoxy by filling carbon nanotube, eXPRESS. eXPRESS Polym Lett. 2008; 2(1):40-8.

13. Ma PCh, Kim J-K, Tang BZ. Effects of silane functionalization on the properties of carbon nanotube/epoxy nanocomposites. Compos Sci Technol. 2007;67:2965-72.

14. Liu L, Wagner HD. A comparison of the mechanical strength and stiffness of MWNT-PMMA and MWNT-epoxy nanocomposites. Compos Interfaces. 2007;14(4):285-97.

15. Chang TC, Chiu YS, Chen HB, Ho SY. Degradation of phosphorus-containing polyurethanes. Polym Degrad Stab. 1995;47: 375-81.

16. Park JG, Cheng Q, Lu J, Bao J, Li S, Tian Y, Liang Z, Zhang C, Wang B. Thermal conductivity of MWCNT/epoxy composites: The effects of length, alignment and functionalization. Carbon 2012. doi:10.1016/j.carbon.2011.12.046. 